\title{
Uma revisão bibliográfica dos fatores de influência no ensaio esclerométrico
}

\section{A review of the influencing factors in the sclerometric assay}

Article Info:

Article history: Received 2021-03-29 / Accepted 2021-03-29 / Available online 2021-03-30

doi: 10.18540/jcecvl7iss1pp12100-01-09e

\author{
Mayanne Vieira de Paiva \\ https://orcid.org/0000-0002-5846-783X \\ Instituto de Engenharia do Araguaia IEA/UNIFESSPA, Brasil \\ E-mail: mayvieirap@gmail.com.br \\ Marcus Vinícius Pereira Freitas \\ https://orcid.org/0000-0001-9333-2183 \\ Instituto de Engenharia do Araguaia IEA/UNIFESSPA, Brasil \\ E-mail: mvpfreitas@unifesspa.edu.br \\ Carlos Eduardo Soares \\ https://orcid.org/0000-0003-1048-606X \\ Universidade Federal do Sul e Sudeste do Pará, UNIFESSPA, Brasil \\ E-mail: carlossoaresagro@outlook.com.br
}

\section{Resumo}

As patologias existentes nas edificações de concreto armado ocorrem em função de diversas variáveis, uma das principais é a falta de controle tecnológico durante a obra, a partir do qual é possível prever ou detectar "não conformidades". A falta ou falha nesse controle pode ocasionar problemas nas estruturas, portanto, os ensaios não destrutivos (ENDs) surgiram como métodos para se estimar a resistência do concreto e verificar a necessidade de reparos ou reforços nas estruturas. O Ensaio Esclerométrico é um END que mede a dureza superficial do concreto, fornecendo elementos para a avaliação da qualidade do concreto em estruturas novas ou antigas, auxiliando na identificação e prevenção de danos associados à durabilidade e segurança estrutural. Este trabalho objetiva realizar uma revisão sobre o ensaio de esclerometria e suas particularidades, bem como analisar os principais fatores que influenciam no ensaio. Buscou-se esclarecer questões acerca das vantagens e limitações da esclerometria e promover conhecimentos sobre a realização do ensaio através de uma revisão bibliográfica que apresenta debates entre normas vigentes relativas ao tema e literaturas publicadas sobre alguns fatores específicos, sendo estes: mão de obra, tipos de cimento e carbonatação, além de apresentar ensaios que auxiliam na análise do índice esclerométrico.

Palavras-chave: Patologias. Esclerometria. Controle tecnológico.

\begin{abstract}
The existing pathologies in reinforced concrete buildings occur due to several variables, one of the main ones is the lack of technological control during the construction, from which it is possible to predict or detect "non-conformities". The lack or failure in this control can cause problems in structures, therefore, non-destructive tests (NDTs) emerged as methods to estimate the strength of the concrete and verify the need for repairs or reinforcements in the structures. The Sclerometric Test is an NDT that measures the surface hardness of concrete, providing elements for assessing the quality of concrete in new or old structures, helping to identify and prevent damage associated with durability and structural safety. This work aims to review the sclerometry test and its particularities, as well as to analyze the main factors that influence the test. Sougth to clarify questions about the advantages and limitations of sclerometry and to promote knowledge about the performance of the essay through a bibliographic review that presents debates between current norms related to the theme and published literature on some specific factors, these being: labor, types of cement and carbonation, besides presenting tests that help in the analysis of the sclerometric index.
\end{abstract}


Keywords: Pathologies. Sclerometry. Technological control.

\section{Introdução}

As patologias que ocorrem nas edificações são resultado de diversas variáveis, a falta de controle tecnológico durante a obra é uma dos principais causas dessa ocorrência. A partir do controle tecnológico é possível prever ou detectar "não conformidades" e a falta ou falha nesse processo pode comprometer a qualidade e durabilidade das estruturas. Ambientes marinhos e urbanos também contribuem para a degradação das estruturas, como é o caso das regiões litorâneas brasileiras, onde há um grande número de estruturas de concreto armado, que sofrem degradação agressiva por estarem expostas ao ambiente marinho.

Araújo (2018) observou e correlacionou estudos que avaliaram causas das principais manifestações patológicas em João Pessoa-PB. Como resultado, os trabalhos estudados pela autora destacaram que estas manifestações patológicas estão ocorrendo cada vez mais cedo, sendo a corrosão das armaduras, as infiltrações e as fissuras os principais tipos observados, causadas por um concreto muito permeável, má impermeabilização das estruturas e rigidez inadequada dos elementos estruturais, respectivamente. Ainda de acordo com Araújo (2018), a avaliação descrita nos estudos analisados induz que as manifestações patológicas estão associadas não somente ao ambiente agressivo em que se encontram as estruturas, mas à falta de controle tecnológico do concreto e como os estudos analisados apresentam uma diferença de 14 anos de um para o outro, a autora afirma que é perceptível que não houveram muitos avanços para prevenção contra incidência desses problemas.

Os ensaios não destrutivos (ENDs) surgiram como métodos realizados para se estimar a resistência do concreto e verificar a necessidade de reparos ou reforços, tais métodos foram desenvolvidos em busca de avaliar a qualidade do concreto na estrutura e são considerados "aqueles que não causam nenhum dano no elemento ensaiado, ou deixam pequenos danos para serem reparados após o ensaio. Eles não provocam perda na capacidade resistente do elemento" (EVANGELISTA, 2002, p.4), se apresentando como alternativas eficazes e de baixo custo. Para comprovar que o concreto utilizado na execução da estrutura atende as exigências estabelecidas no projeto, são feitos ensaios de resistência à compressão, normalmente aos 28 dias, em corpos de prova cilíndricos ou cúbicos, os quais são moldados, curados e rompidos de acordo com as normas técnicas vigentes para cada país (ESCOBAR, 2011). No entanto, esses corpos de prova não representam uma amostra fidedigna do concreto que existe na estrutura pois as condições de lançamento, adensamento e cura podem ser diferentes da obra.

O Ensaio Esclerométrico é um END definido pela NBR 7584 como o “método não destrutivo que mede a dureza superficial do concreto, fornecendo elementos para a avaliação da qualidade do concreto endurecido" (ABNT, 2012, p.1). A falta de conhecimento de muitos profissionais sobre as particularidades desse ensaio, frequentemente ocasiona erros durante a execução e também na análise dos resultados, podendo apresentar uma falsa resistência do concreto e invalidar a avaliação, portanto, é imprescindível a utilização de mão de obra devidamente capacitada para a realização deste procedimento.

De acordo com Evangelista (2002) esse método é relevante não somente para o caso de estruturas executadas há algum tempo, mas também para o caso de estruturas recentes ou ainda em execução, pois a peça estrutural avaliada não sofre danos e é possível realizar maior quantidade de ensaios. Em estruturas novas, eles podem ser aplicados para monitoramento da evolução da resistência ao longo do tempo ou para aferir a qualidade do concreto, pois o surgimento de patologias em elementos de concreto não está vinculado somente com a idade da obra, mas também com a mão de obra e materiais utilizados, já os ensaios em estruturas existentes tem por finalidade avaliar a integridade estrutural e a capacidade de resistir às solicitações (ESCOBAR, 2011). Visto que a esclerometria auxilia na identificação e prevenção de danos estruturais associados à segurança estrutural e durabilidade, fica evidente a importância da realização de pesquisas a respeito do tema. 
Diante do exposto, este trabalho objetiva realizar uma revisão bibliográfica sobre o ensaio de esclerometria e suas particularidades, bem como analisar os principais fatores que influenciam no ensaio. De forma mais específica, buscou-se esclarecer questões acerca das vantagens e limitações da esclerometria e promover conhecimentos sobre a realização do ensaio, apresentando debates entre as normas vigentes relativas ao tema e literaturas publicadas sobre os fatores: mão de obra, tipos de cimento e carbonatação, que influenciam diretamente na realização e na análise do índice esclerométrico.

\section{Metodologia}

A pesquisa bibliográfica foi realizada com a finalidade de elaborar uma revisão empírica, mostrando como os fatores que influenciam os resultados do ensaio de esclerometria estão sendo estudados e como afetam nos resultados desse ensaio. Para a realização do levantamento, utilizouse como fonte de pesquisa a base de dados do portal Capes, revistas voltadas para a área de patologias e estruturas, e a ferramenta Google Scholar. A metodologia para pesquisa dos trabalhos baseou-se em buscar trabalhos correlacionados com o tema por meio de palavras chaves, os trabalhos levantados foram filtrados de acordo com o que apresentavam em seus resumos e conclusões. Os trabalhos selecionados foram lidos detalhadamente e os principais tópicos voltados para o tema foram apresentados nesse trabalho.

\section{Referencial teórico}

Nesta seção, serão apresentados os assuntos relevantes para análise e desenvolvimento do tema.

\subsection{Histórico}

Durante os anos 30 se iniciaram as primeiras tentativas para medir a dureza superficial do concreto com base no princípio do ricochete, que define que a massa elástica depende da superfície onde ela se choca, esse conceito foi amplamente aceito. Inicialmente este método era empírico e consistia em aplicar uma força com um martelo no concreto, "sua dureza era determinada pelo som produzido e pela altura que o martelo subia após o choque" (BAUER, 2008).

De acordo com Thomaz (2007), o esclerômetro de reflexão foi criado em 1948 pelo engenheiro suíço Enerst Schmitd, aparelho esse que mede a dureza superficial do concreto e a correlaciona com a resistência à compressão desse concreto. Com o avanço das tecnologias construtivas, houve uma crescente preocupação em analisar a durabilidade e patologias nas edificações, o que difundiu a realização dos ensaios não destrutivos. Atualmente, o ensaio esclerométrico é muito utilizado em obras em execução, para avaliar a resistência do concreto em corpos de prova que deram resultado abaixo do esperado. Também é utilizado para estimar a resistência do concreto de obras antigas (THOMAZ, 2007). A figura 1 apresenta um modelo de esclerômetro mais atual, sendo aplicado na realização do ensaio de esclerometria. 


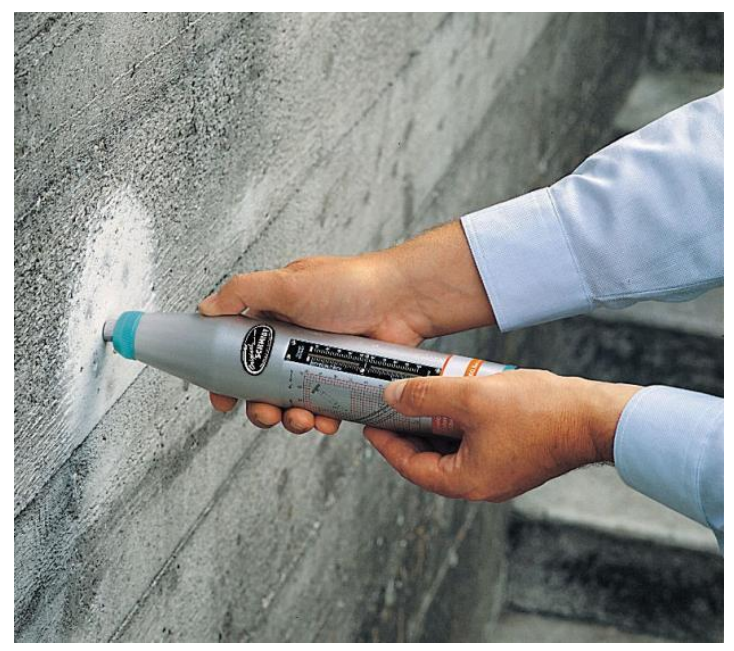

Figure 1 - Esclerômetro de reflexão em uso. (Thomaz, 2007)

\subsection{Normas vigentes}

Há diversas normas que orientam a realização do ensaio esclerométrico, a maioria são internacionais e, de uma forma geral, descrevem métodos bem similares, com algumas distinções. No Brasil, a norma que define e direciona o ensaio esclerométrico é a NBR 7584: 2012 Concreto endurecido - Avaliação da dureza superficial pelo esclerômetro de reflexão - Método de Ensaio, sendo esta sua segunda edição. Entre as modificações realizadas entre a versão anterior (1995) e a atual, destacam-se a determinação de 16 pontos de impacto que antes era de no mínimo 9 e máximo 16 pontos, e a inclusão dos anexos: A - campo de aplicação, B - aplicação do esclerômetro e C fatores que influenciam os resultados do ensaio. Neste último anexo, alguns dos fatores listados são os tipos de cimento, tipos de agregados e tipos de superfície, além da carbonatação, operação do esclerômetro entre outros.

Existe também a Norma Mercosul NM 78:1996 Concreto endurecido - Avaliação da dureza superficial pelo esclerômetro de reflexão, da Associação Mercosul de Normalização (AMN), elaborada pelo CSM 05 - Comitê Setorial de Cimento e Concreto, que é bem similar à norma brasileira. A principal diferença é a orientação para obtenção de curvas de correlação entre o ensaio de esclerometria e a resistência à compressão do concreto, apresentada no anexo $\mathrm{C}$ da norma. Como ressalta Evangelista (2002), as normas Mercosul além da metodologia de ensaio, também apresentam o procedimento para realizar curvas de correlação, enquanto que as normas brasileiras para esclerometria apresentam apenas a metodologia de execução dos ensaios.

\subsection{Fatores de influência}

São muitos os fatores que podem causar interferência na esclerometria, contudo, os erros ligados à falha humana são os mais relevantes pois são possíveis de serem evitados. Outros fatores se devem ao meio e às condições as quais a estrutura está submetida, sejam quais forem as causas, as manifestações patológicas existentes devem ser cuidadosamente inspecionadas e levadas em conta no ensaio pois podem interferir nos resultados. A NBR 7584 orienta que para a realização de um ensaio esclerométrico, devem ser evitadas superfícies irregulares, ásperas, curvas ou talhadas, pois podem não fornecer valores homogêneos, superfícies úmidas ou carbonatadas também devem ser evitadas (ABNT,2012).

Em vista disso, esta seção apresenta e exemplifica a seguir, três fatores de influência considerados relevantes para o estudo do ensaio de esclerometria.

Mão de obra: Durante a realização dos ENDs, da esclerometria em específico, é importante garantir a qualidade e treinamento da mão de obra envolvida, visto que é um ensaio que requer precisão na execução para gerar dados confiáveis. O esclerômetro deve ser operado por um 
profissional capacitado para tal, pois durante a operação é preciso imprimir pressões uniformes sobre a superfície de ensaio, conforme NBR 7584 (ABNT, 2012).

A tecnologia atual possibilitou a criação de esclerômetros intuitivos, que detectam e corrigem o ângulo de impacto automaticamente, registram e avaliam a série diminuindo a influência do operador e consequentemente prevenindo falhas humanas como erros de leitura e de transcrição. Além disso, os novos aparelhos permitem economia de tempo na revisão manual e evitam a perda de medições anotadas à mão, pois, os dados são armazenados em uma nuvem (PROCEQ, 2019). Entretanto, apesar da modernização dos aparelhos gerar mais confiança nos resultados, a capacitação profissional ainda se faz extremamente necessária durante a realização de qualquer tipo de ensaio, além de ser exigida em norma.

Tipos de cimento: Como o tipo e a quantidade do cimento utilizado influencia diretamente na rigidez do concreto, o valor do índice esclerométrico também pode ser afetado. Segundo a NM 78, o consumo de cimento por $\mathrm{m}^{3}$ de concreto não tem influência relevante, entretanto o tipo de cimento tem influência muito significativa na obtenção do valor de reflexão, concretos feitos com cimentos aluminosos ou supersulfatados $(80 \%$ a $85 \%$ de escória de alto forno $+10 \%$ a $15 \%$ de sulfato de cálcio) apresentam correlações diferentes da calibração obtida com um cimento Portland comum (AMN, 1996). Em concordância com esta norma, a NBR 7584 acrescenta que é necessário recorrer a novas correlações sempre que houver mudança do tipo de cimento (ABNT, 2012). Araújo (2018) recomenda a utilização de curvas de correlação próprias para uma análise mais confiável de determinado concreto, embora a curva fornecida pelo aparelho possa ser válida para alguns casos.

Conforme relaciona Evangelista (2002), há algumas normas que concordam que o tipo de cimento influencia o índice esclerométrico (IE), em especial cimentos com alto teor de escória de alto forno. Essa influência também ocorre na correlação entre o IE e o valor de resistência à compressão, para o caso de ensaios executados em corpos de prova. Em sua pesquisa, a autora utilizou concretos com cimento Portland de alto-forno (CP III-32) e cimento Portland de alta resistência inicial (CP V ARI) e verificou que há uma grande diferença nos índices esclerométricos obtidos. A série de concreto com CP V ARI apresenta os valores do IE mais altos devido à hidratação mais rápida do cimento, gerando índices de $13 \%$ a $70 \%$ maiores que os concretos com CP III-32.

O índice esclerométrico representa o valor de reflexão do aparelho sobre a superfície do concreto, desta forma, é esperado que apresente valores mais altos para concretos com maior dureza superficial, o que se confirma através das normas ABNT NR 7584 (2012) e AMN NM 78 (1996) analisadas, as quais concordam que o tipo de cimento tem influência sobre o valor do IE, principalmente para concretos feitos com cimento pozolânico, resistente à sulfatos e de alta resistência inicial, que, segundo explica Evangelista (2002) deve-se ao baixo calor de hidratação que estes cimentos possuem.

Carbonatação do concreto: $\mathrm{O}$ aumento da concentração de gás carbônico $\left(\mathrm{CO}_{2}\right)$ na atmosfera afeta diretamente as estruturas de concreto, principalmente em edificações da área urbana, através da carbonatação. Esse processo físico-químico é uma reação em que o hidróxido de cálcio $\mathrm{Ca}(\mathrm{OH})_{2}$ do cimento é consumido pela dissolução do $\mathrm{CO}_{2}$, reduzindo o $\mathrm{pH}$ do concreto e comprometendo sua capacidade de proteger quimicamente as armaduras de aço, o que afeta o ciclo de vida das estruturas e reduz sua durabilidade, quanto maior a concentração de $\mathrm{CO}_{2}$ no concreto, menor será seu pH, e maior será sua camada carbonatada (SOUSA e GOMES, 2018).

As características do concreto, as condições de exposição e a temperatura influenciam no avanço da carbonatação, aumentando a velocidade da reação. Existem várias técnicas para se determinar a profundidade de carbonatação, a mais utilizada é a de indicadores de $\mathrm{pH}$, com o uso de fenolftaleína (Figura 2), no qual a parte carbonatada com $\mathrm{pH}$ abaixo de 9 fica incolor, e as áreas com pH maior que 9 apresentam uma coloração vermelho carmim (SOUSA e GOMES, 2018). 

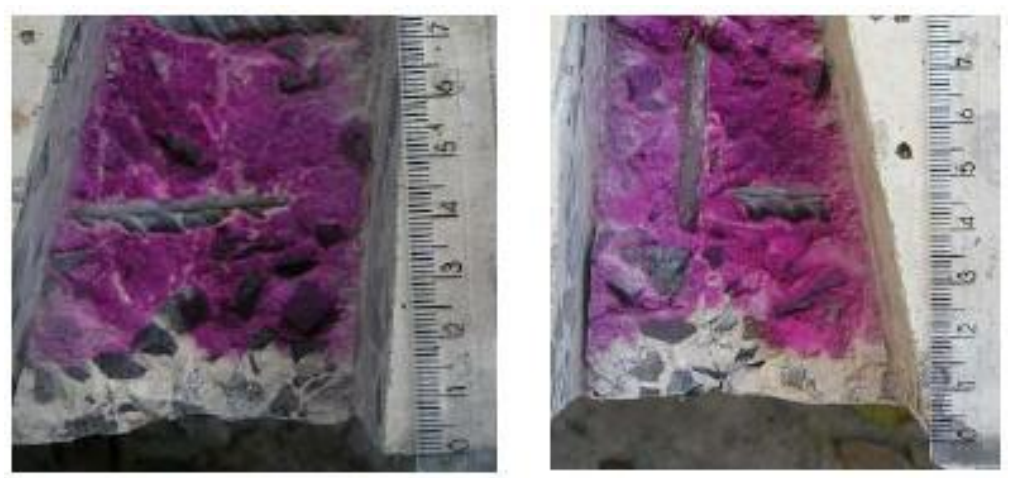

Figure 2 - Medição da carbonatação (Silva e Libório, 2005).

A NBR 7584 orienta que o ensaio esclerométrico deve ser evitado em superfícies carbonatadas, mas que caso se deseje ensaiá-las devem ser adequadamente preparadas e aplicados coeficientes de correção, que devem ser apresentados nos resultados do ensaio (ABNT, 2012). Campos (2019) alega que apesar dessa norma mostrar que a carbonatação é um dos fatores que tem influência no ensaio de esclerometria, o tamanho dessa influência não é mensurado, fazendo com que haja apenas um aspecto qualitativo da relação entre a carbonatação e o ensaio de esclerometria. Portanto essa quantificação é realizada através de estudos que mostram o quanto a carbonatação influencia os ensaios de esclerometria, através de métodos como o uso de corpos de prova com diferentes tempos de exposição ao $\mathrm{CO}_{2}$. Sousa e Gomes (2018) explicam que o valor da profundidade de carbonatação é utilizado para corrigir o índice esclerométrico, pois a carbonatação influencia nos resultados da resistência superficial da estrutura. Ainda segundo os autores, com a introdução do $\mathrm{CO}_{2}$ para o interior do concreto, ocorre a formação de carbonato de cálcio nos poros, o que torna a superfície do concreto mais densa e interfere na reflexão do esclerômetro.

Entre algumas das formas de se correlacionar esses dados, podem ser utilizadas curvas de correlação ou gráficos, como exemplifica a figura 3, na qual os parâmetros medidos estão em milímetros e onde é possível observar que o índice esclerométrico aumenta de acordo com aumento da profundidade de carbonatação confirmando o que se afirma na literatura (SOUSA E GOMES, 2018). Para análise desses valores, a espessura da camada de cobrimento do concreto existente também deve ser observada, uma vez que a frente de carbonatação pode atingir as armaduras e causar deterioração das estruturas caso o cobrimento não siga as normas e apresente espessura inferior do que o recomendado.

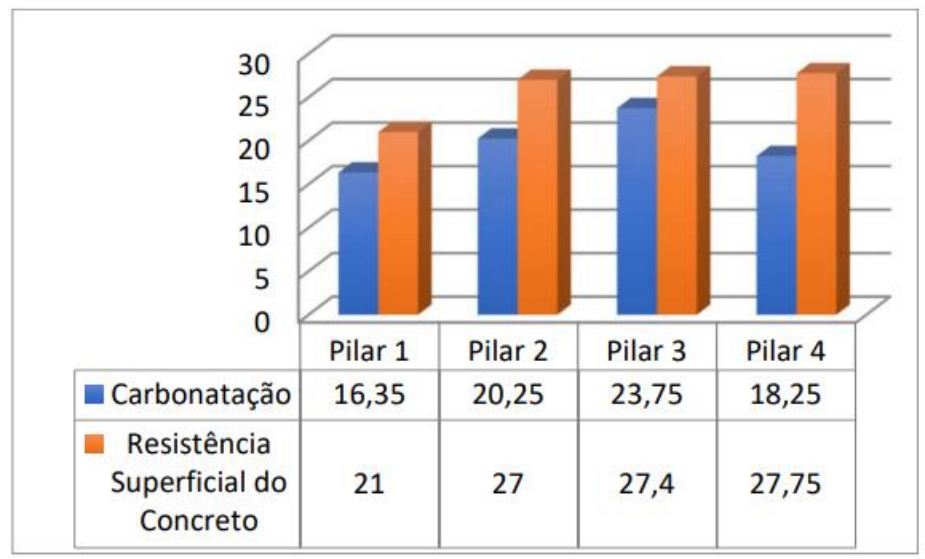

Figure 3 - Gráfico carbonatação x resistência superficial do concreto (Sousa e Gomes, 2018).

A NBR 7584 adverte que em superfícies carbonatadas, os valores para a resistência do concreto podem ser superestimados em mais de 50\%, devido á espessura da camada carbonatada (ABNT, 2012). A influência da carbonatação pode ser significativa em concretos com idade superior a 3 meses, pois após esse período a camada superficial de $30 \mathrm{~mm}$ à $50 \mathrm{~mm}$, deixa de representar o concreto no interior da peça (EVANGELISTA, 2002). Embora a velocidade de difusão do $\mathrm{CO}_{2}$ 
diminua com o tempo por causa da densificação dos poros, a evolução desse processo de carbonatação deve ser acompanhada para detectar a necessidade de reparos ou reforços na estrutura com base na vida útil restante, que pode ser estimada através de ensaios não destrutivos como a esclerometria (SOUSA e GOMES, 2018).

\subsection{Ensaios auxiliares}

Visto que há diversos fatores que influenciam a obtenção dos índices esclerométricos, a eficácia do método é melhor observada quando este é combinado com outros ensaios e utilizadas curvas de correlação apropriadas. Como define a NBR 7584, "o método esclerométrico não pode ser considerado substituto de outros métodos, mas um método adicional ou um ensaio complementar" (ABNT, 2012, p.7). Escobar (2011) realizou um estudo experimental correlacionando o índice esclerométrico com a resistência à compressão axial do concreto em corpos de prova cúbicos e cilíndricos, o autor afirma que embora os resultados tenham apresentado divergências na correlação dos valores, o método de esclerometria não deve ser descartado pois "a confiabilidade do método quando se deseja avaliar a resistência à compressão é tanto maior quanto melhor for o conhecimento da composição do concreto sob investigação" (ESCOBAR, 2011, p.16). A figura 4 exemplifica a correlação entre a resistência à compressão e o índice esclerométrico de três classes de concreto através de uma curva de correlação geral, onde estão representados dados experimentais em um único conjunto.

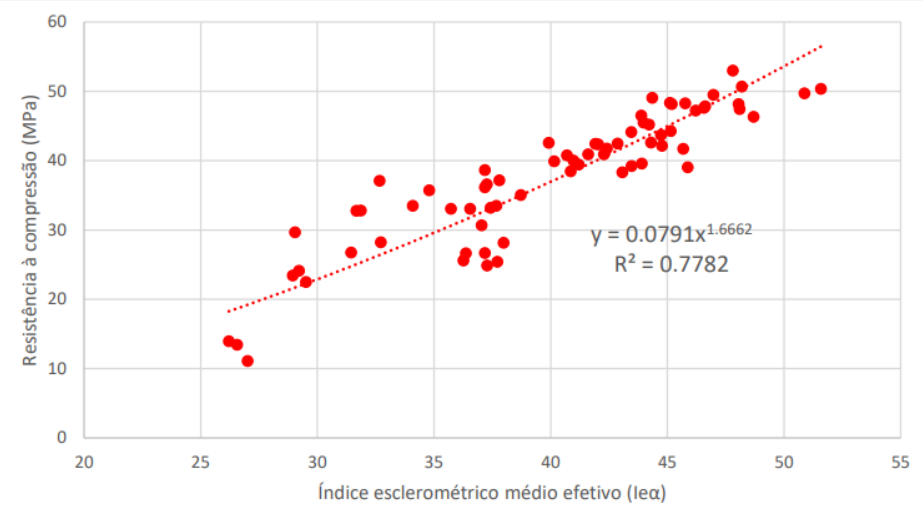

Figure 4 - Exemplo de curva de correlação geral (Araújo, 2018).

A resistência à compressão, resistência à tração e módulo de elasticidade são as principais propriedades mecânicas analisadas nas estruturas de concreto. Segundo Araújo (2018), os ENDs mais empregados para obter indiretamente essas propriedades são a esclerometria e o ultrassom, outros métodos também são utilizados com essa finalidade, como a resistividade elétrica superficial, analisada pelo autor em seu estudo.

Evangelista (2002) estudou a correlação entre a resistência à compressão do concreto e valores obtidos por meio de ENDs como velocidade de propagação de ondas ultrassônicas e índice esclerométrico, realizados em corpos de prova com 30 tipos de cimento, no qual a autora analisou a influência de vários fatores nas grandezas medidas e nas curvas de correlação utilizadas. Machado (2005) afirma que a aplicação do método combinado da velocidade do ultrassom com a esclerometria tem sido proposta para se estimar a resistência à compressão do concreto com maior precisão.

Como observado, o ensaio esclerométrico é amplamente utilizado como método complementar para se estimar algumas propriedades mecânicas do concreto, através de métodos combinados e correlação de resultados, utilizado principalmente com os ensaios de resistência à compressão axial, propagação de ondas ultrassônicas, resistividade elétrica superficial, perfuração de pinos, pull-off entre outros. 


\section{Conclusões}

O ensaio de esclerometria demonstra ser uma ferramenta importante para a engenharia civil por proporcionar uma análise mais abrangente da estrutura de concreto armado, podendo ser empregado em edificações novas, antigas ou em construção. $\mathrm{O}$ equipamento utilizado é leve, de fácil manuseio e custo baixo, gerando grande quantidade de dados de forma rápida. Os danos que podem ser causados na superfície são praticamente nulos, deixando pequenas marcas em concretos novos ou de baixa resistência. O método é eficaz para avaliar a uniformidade do concreto, monitorar o desenvolvimento da resistência ao longo do tempo e para se estimar a resistência do concreto, porém, conforme observado, as normas brasileiras referentes ao ensaio são limitadas à metodologia e não apresentam orientações para elaboração de curvas de correlação, levando os pesquisadores a buscarem normas internacionais para basearem seus trabalhos, o que pode não corresponder aos métodos aplicáveis em solo nacional.

O estudo das aplicações e fatores de influência no ensaio esclerométrico podem potencializar os resultados obtidos pois apresentam informações essenciais para uma análise mais precisa. Em relação a mão de obra, apesar de ser imprescindível para realização do ensaio de esclerometria, verificou-se uma escassez de literaturas publicadas significativas que abordem este tema, demonstrando uma lacuna na área de pesquisa que seria interessante ser analisada para enriquecer a capacitação profissional e fornecer material de apoio acessível e confiável sobre a realização prática do método. Quanto ao tipo de cimento, observou-se que quanto maior a resistência do cimento utilizado e mais baixo seu calor de hidratação, mais o índice esclerométrico será influenciado, apresentando valores superestimados em até $70 \%$, portanto, é necessário ter o conhecimento da composição química do concreto utilizado na estrutura a ser ensaiada, o que contribui para uma melhor análise dos resultados e possibilita o estabelecimento de curvas de correlação adequadas para cada tipo de cimento e agregados utilizados.

A principal limitação do ensaio estudado se deve aos fatores que influenciam a superfície do concreto como a carbonatação, que eleva o índice esclerométrico e fornece valores que não representam o concreto nas partes mais profundas. De acordo com os estudos analisados, a profundidade de carbonatação encontrada pode ser atribuída à elevada temperatura característica da região, à presença constante de umidade, exposição à ambientes com altas concentrações de $\mathrm{CO} 2 \mathrm{e}$ elevada porosidade do concreto utilizado, o que compromete sua qualidade e durabilidade, portanto, são fatores a serem considerados na avaliação da estrutura que se pretende ensaiar. O ensaio de esclerometria apresenta potencial a ser explorado como ensaio complementar, uma vez que sua aplicação é amplamente recomendada em conjunto com outros métodos, demonstrando eficácia principalmente combinado ao método de propagação de ondas ultrassônicas, mas essa combinação depende das propriedades do concreto que se deseja analisar. A empregabilidade do método como ensaio independente ainda é uma área a ser verificada, visto que sua confiabilidade ainda é muito questionada no meio científico.

O aprimoramento de ensaios não destrutivos no Brasil ainda é um campo vasto a ser explorado, com objetivo de obter resultados mais confiáveis, formar mão de obra qualificada e direcionar os procedimentos adotados para relacionar os índices obtidos em ENDs com a resistência à compressão do concreto. $\mathrm{O}$ uso adequado dos materiais, treinamento da equipe, controle de qualidade mais rígido e acompanhamento tecnológico são investimentos que podem amenizar os problemas que frequentemente ocorrem em obras. Especialistas advertem que ao ignorar esses princípios básicos pode encarecer o empreendimento em até cinco vezes o seu preço inicial, desta forma, este trabalho buscou contribuir para a análise dos fatores que influenciam o ensaio de esclerometria e para difundir conhecimentos que possam melhorar a realização deste método. 


\section{Referências}

ABNT ASSOCIAÇÃO BRASILEIRA DE NORMAS TÉCNICAS. NBR 7584: Concreto endurecido - Avaliação da dureza superficial pelo esclerômetro de reflexão. Rio de Janeiro, $1995.9 \mathrm{p}$.

ABNT ASSOCIAÇÃO BRASILEIRA DE NORMAS TÉCNICAS. NBR 7584: Concreto endurecido - Avaliação da dureza superficial pelo esclerômetro de reflexão - Método de Ensaio. Rio de Janeiro, 2012. 10 p.

Araújo, C. C. (2018). Estudo de correlações entre propriedades do concreto e ensaios não destrutivos. Dissertação de Mestrado, Universidade Federal da Paraíba, João Pessoa, PB, Brasil.

ASSOCIAÇÃO MERCOSUL DE NORMALIZAÇÃO. NM 78: Concreto endurecido - Avaliação da dureza superficial pelo esclerômetro de reflexão. 1996. 13 p.

Bauer, L. A. F. (2008). Materiais de construção. Vol 1. 5. ed. Rio de Janeiro: LTC.

Campos, M. O. (2019). Influência da carbonatação no ensaio de esclerometria. Trabalho de Conclusão de Curso, Universidade Federal do Ceará, Russas, CE, Brasil.

Escobar, C. J.; Cruz, D. A.; Fabro, G. (2011). Avaliação de desempenho do ensaio de esclerometria na determinação da resistência do concreto endurecido. Ibracon. Anais do $50^{\circ}$ congresso brasileiro do concreto - cbc2008 - 50cbc0636. São Paulo, SP, Brasil.

Evangelista, A. C. J. (2002). Avaliação da resistência do concreto usando diferentes ensaios não destrutivos. Tese de Doutorado, Universidade Federal do Rio de Janeiro, Rio de Janeiro, RJ, Brasil.

Machado, M. D. (2005). Curvas de Correlação para Caracterizar Concretos Usados no Rio de Janeiro por Meio de Ensaios Não Destrutivos. Dissertação de Mestrado, Universidade Federal do Rio de Janeiro, Rio de Janeiro, RJ, Brasil.

PROCEQ. Original Schmidt Live - O esclerômetro para concreto de valor de rebote $R$ mais avançado do mundo. 2019.2 Disponível em: <https://www.proceq.com/uploads/tx_proceqproductcms/import_data/files/Original_Schmid t_Live_Sales_Flyer_Portuguese_high.pdf>. Acesso em 03 de outubro de 2020.

Silva, V. M.; Libório, J. B. L. (2005). Comportamento da carbonatação em vigas pré-moldadas de concreto. $1^{\circ}$ Encontro Nacional de Pesquisa-Projeto-Produção em Concreto Pré-moldado. São Carlos, SP, Brasil.

Sousa, P. A.; Gomes, T. (2018) Estudo dos efeitos da carbonatação na vida útil de pontes de concreto armado. Engineering Sciences, v.6, n.2, p.1-11. http://doi.org/10.6008/CBPC2318$\underline{3055.2018 .002 .0001}$

Thomaz, E. C. S. Esclerômetro. 2019. Disponível em: $<$ http://aquarius.ime.eb.br/ webde2/prof/ethomaz/esclerometro01.pdf $>$. Acesso em 22 de setembro de 2020. 